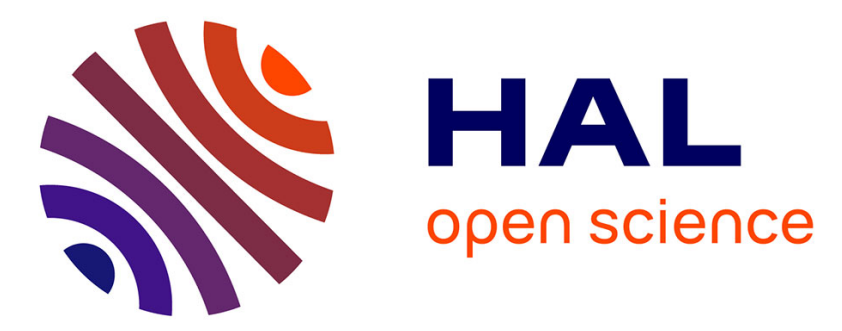

\title{
Size-characterization of natural and synthetic polyisoprenes by Taylor dispersion analysis
}

Jean-Philippe Biron, Frédéric Bonfils, Luca Cipelletti, Hervé Cottet

\section{To cite this version:}

Jean-Philippe Biron, Frédéric Bonfils, Luca Cipelletti, Hervé Cottet. Size-characterization of natural and synthetic polyisoprenes by Taylor dispersion analysis. Polymer Testing, 2018, 66, pp.244-250. 10.1016/j.polymertesting.2018.01.017 . hal-01837505

\section{HAL Id: hal-01837505 https://hal.science/hal-01837505}

Submitted on 26 May 2020

HAL is a multi-disciplinary open access archive for the deposit and dissemination of scientific research documents, whether they are published or not. The documents may come from teaching and research institutions in France or abroad, or from public or private research centers.
L'archive ouverte pluridisciplinaire HAL, est destinée au dépôt et à la diffusion de documents scientifiques de niveau recherche, publiés ou non, émanant des établissements d'enseignement et de recherche français ou étrangers, des laboratoires publics ou privés.

\section{(c)(1)}

Distributed under a Creative Commons Attribution| 4.0 International License 


\section{Accepted Manuscript}

Size-characterization of natural and synthetic polyisoprenes by Taylor dispersion analysis

Jean-Philippe Biron, Frédéric Bonfils, Luca Cipelletti, Hervé Cottet

PII:

S0142-9418(17)31611-2

DOI:

10.1016/j.polymertesting.2018.01.017

Reference: POTE 5303

To appear in: Polymer Testing

Received Date: 12 November 2017

Accepted Date: 22 January 2018

Please cite this article as: J.-P. Biron, Fréé. Bonfils, L. Cipelletti, Hervé. Cottet, Size-characterization of natural and synthetic polyisoprenes by Taylor dispersion analysis, Polymer Testing (2018), doi: 10.1016/ j.polymertesting.2018.01.017.

This is a PDF file of an unedited manuscript that has been accepted for publication. As a service to our customers we are providing this early version of the manuscript. The manuscript will undergo copyediting, typesetting, and review of the resulting proof before it is published in its final form. Please note that during the production process errors may be discovered which could affect the content, and all legal disclaimers that apply to the journal pertain. 
Size-characterization of natural and synthetic polyisoprenes by Taylor dispersion analysis

\begin{abstract}
Jean-Philippe Biron ${ }^{1}$, Frédéric Bonfils ${ }^{2}$, Luca Cipelletti ${ }^{3}$ and Hervé Cottet $^{1 *}$
\end{abstract}
${ }^{1}$ IBMM, University of Montpellier, CNRS, ENSCM, Montpellier, France

${ }^{2}$ IATE, University of Montpellier, CIRAD, INRA, Montpellier Sup Agro, Montpellier, France

${ }^{3}$ L2C, University of Montpellier, CNRS, Montpellier, France

* CORRESPONDING AUTHOR: Prof. Hervé Cottet

Tel: +33 46714 3427, Fax: +33 46763 1046. E-mail: herve.cottet@umontpellier.fr 
ABSTRACT: Non-aqueous Taylor Pdispersion analysis (TDA) was used for the sizecharacterization of natural and synthetic polyisoprenes $\left(4 \times 10^{3}-2 \times 10^{6} \mathrm{~g} / \mathrm{mol}\right.$ molar mass). Not only the weight-average hydrodynamic radius $\left(R_{h}\right)$, but also the probability distribution of the hydrodynamic radius, were both derived from the Taylorgrams by a simple integration of the elution profile and by a more sophisticated constrained regularized linear inversion of the Taylorgram, respectively. Results in terms of size characterization (hydrodynamic radii between 2 and $100 \mathrm{~nm}$ ) were compared to size exclusion chromatography coupled to a refractive index-based mass detector. Multimodal size distributions were resolved by TDA for industrial and natural polyisoprenes, with the advantage over the chromatographic technique that, in TDA, there is no abnormal elution of microaggregates (hydrodynamic radii $\sim 40-50$ $\mathrm{nm})$. Considering the importance and the difficulty of characterizing polyisoprene microaggregates, TDA appears as a promising and simple technique for the characterization of synthetic and natural rubber.

Key Words: polyisoprene; natural rubber; Taylor dispersion analysis; hydrodynamic radius; diffusion coefficient; size distribution.

Title Running Head. Taylor dispersion analysis of synthetic and natural rubbers 


\section{Introduction}

Natural rubber (NR) is a biopolymer produced from latex of Hevea brasiliensis trees. NR is used to prepare many goods, the main one being tires that absorb nearly $70 \%$ of the 12 million tons annually worldwide. As an agro-material produced by a tree, NR exhibits rather variable properties for many reasons (genotype of the tree [1-2], season [3], maturation of coagula [4-6], etc.). Thus, as for other polymeric materials used in industrial applications, it is important to characterize the NR macromolecular structure as a prelude to predicting NR end-use properties [7-8].

Natural rubber has a very specific associative structure. When dispersed in good solvents for polyisoprene, NR presents a soluble fraction and an insoluble fraction, often referred to as "macrogel" [9-10] or "gel phase" [11-12]. The composition of the soluble part is also specific as it contains two main entities: ( $I$ ) polyisoprene linear macromolecules of different lengths, with a random coil structure, and (ii) very compact microaggregates or microgels (sphere-like structure) [13-15]. Links between non-isoprene compounds (lipids, proteins, and/or mineral elements) and the polyisoprene chains are thought to be the main reason for the macrogel formation in NR [12, 16-17]. Although an international standard (ISO 16564) exists to characterize the NR macromolecular structure by size exclusion chromatography (SEC) or gel permeation chromatography (GPC), the development of new analytical techniques is still required to improve the characterization of NR using orthogonal or complementary methods.

This paper describes a novel method to characterize the NR macromolecular structure: Taylor dispersion analysis in organic solvent. Taylor Dispersion Analysis (TDA) is an absolute sizing method requiring no calibration and allowing the determination of the diffusion coefficient (or, equivalently, the hydrodynamic radius) of solutes of any size between one angstrom and a few hundred nanometers. TDA is based on the dispersion of a sample band in an open tubular column under Poiseuille flow. The combination of the dispersive parabolic velocity profile with the molecular diffusion of the solute leads to a specific dispersion, called Taylor dispersion. Started with the pioneering work of Taylor on macroscopic tubing [18], TDA is now implemented in narrow capillaries (typically $50 \mu \mathrm{m}$ internal diameter), leading to much faster analysis (a few min) and requiring only tiny sample amounts (a few $\mathrm{nL}$ ) [1922]. In its modern miniaturized version, TDA can be very easily implemented on commercial capillary electrophoresis apparatus. Alternatively, fast TDA can be performed on HPLC equipment at a high linear velocity $\left(\sim 30 \mathrm{~cm} \mathrm{~s}^{-1}\right)$ in a coiled open capillary tube of $250 \mu \mathrm{m}$ i.d. $\times 30 \mathrm{~m}$ typical dimensions, as recently introduced by the Holyst group [23]. In the latter 
configuration, the genuine conditions for the applicability of TDA are not fulfilled [24], however, an empirical correction can be used to get the correct diffusion coefficient [23].

TDA was applied to the characterization of proteins [25-27], macromolecules [28-30], drug delivery systems [31, 32], nanoparticles [21, 33, 34], polyelectrolyte complexes and polyplexes [35], pharmaceutical compounds [36, 37], and micelles or microemulsions [38, 39]. It can also be used for the study of molecular interactions [40, 41]. The application of TDA is not limited to water-soluble solutes, as demonstrated by the size characterization of polystyrenes in THF [28], asphaltenes/bitumen in hexane or THF/acetonitrile mixtures [42, 43], and drugs in pharmaceutical solvents [36]. Basically, TDA yields the weight average hydrodynamic radius when using a mass sensitive detector, such as a UV detector, for a polymer absorbing via the repeating unit [44]. This information is obtained by simple integration of the elution temporal profile (also called Taylorgram). However, we recently demonstrated that more sophisticated data analyses allow one to determine the full hydrodynamic radius distribution, thus providing valuable information on the sample polydispersity $[45,46]$.

In this work, we demonstrate that TDA can be used to get, within a few minutes, the hydrodynamic radius distributions of commercial natural and synthetic polyisoprenes. The data obtained by TDA are compared to those derived from size exclusion chromatography (SEC) coupled to multi-angle static light scattering (MALS).

\section{Experimental}

\subsection{Materials}

The two NR samples used for this study were all TSR (Technically Specified Rubber). Sample NR1 was industrial TSR10 grade prepared by natural coagulation of latex followed by several days of coagulum maturation before processing. This sample was treated with neutral hydroxylamine sulfate (NHS) to stabilize its properties during storage, yielding a TSR10CV grade (CV stands for constant viscosity), a special grade not prone to storage hardening. Sample NR2 was prepared by acid coagulation (formic acid) of fresh field latex. Neutral hydroxylamine sulfate (NHS) was added to the latex prior to coagulation to inhibit storage hardening of rubber [47]. Sample NR2 was TSR5CV grade. Three synthetic industrial cis1,4-polyisoprenes (PI) were used directly as received: IR2200 (NatSyn 2200, Goodyear chemical), IR307 and IR309 (Kraton polymers). Standard linear polyisoprene (PI) of 4.5, 22, $111,307,361,608$ and $766 \times 10^{3} \mathrm{~g} / \mathrm{mol}$ weight-average molar masses were obtained from Polymer Standard Service (PSS, Germany) and were used as received. 


\subsection{Determination of the number- and weight-average molar mass by size exclusion chromatography coupled to multi-angle light scattering (SEC-MALS)}

For all samples, the macromolecular structure was characterized by SEC-MALS, except for standard polyisoprene, for which the number average, $M_{n}$ and mass-average, $M_{w r}$ molar mass were given by the supplier. The samples (30 $\pm 5 \mathrm{mg}$ ), from NR pellets, were dissolved in tetrahydrofuran (THF, $30 \mathrm{~mL}$, HPLC grade, VWR France) stabilized with 2,6-di-tert-butyl-4methylphenol (BHT). The solutions were stored for 7 days in the dark at $30^{\circ} \mathrm{C}$ (during storage, the samples were stirred for $1 \mathrm{~h} /$ day), they were then filtered (Acrodisc $1 \mu \mathrm{m}$, glass fiber, Pall France) and finally injected into the SEC-MALS apparatus. For each sample, three solutions were independently prepared and measured. The SEC equipment comprises an online degasser (EliteTM, Alltech), a Waters 515 pump, a refractive index detector (Waters 2410) and a multi-angle light scattering detector (Dawn DSP, Wyatt Technology). Two Waters HMW6E columns (Styragel HMW columns packed $20 \mu \mathrm{m}$ particles, $300 \mathrm{~mm} \times 7.8 \mathrm{~mm}$ I.D.), maintained at $45^{\circ} \mathrm{C}$, and a guard column (same stationary phase as the two separation columns) were used. The mobile phase was stabilized THF injected at a flow rate of 0.65 $\mathrm{mL} \cdot \mathrm{min}^{-1}$; the injected volume was $150 \mu \mathrm{L}$. The MALS detectors at all 18 angles were calibrated using a THF solution of a polystyrene standard with low polydispersity $\left(M_{w}=30.3\right.$ $\mathrm{kg} \cdot \mathrm{mol}^{-1}$, Wyatt technology). The same solution was used to determine the interconnection volume between the two detectors $(0.235 \mathrm{~mL})$. The basic theory of determining the weightaverage molar mass and radius of gyration for a dilute solution of a macromolecule is well known and described in numerous papers in the literature $[\mathbf{4 8}, \mathbf{4 9}]$. The weight average molar masses and radius of gyration at each slice of the chromatogram were calculated using the Berry method for extrapolation, as implemented in ASTRA software (version 5.3.1, Wyatt technology). The order of polynomial fit for the Berry analysis was two. Twelve angles, from $38.8^{\circ}$ to $138.8^{\circ}$, were used for the analysis. The differential refractive index increment at $\lambda=633 \mathrm{~nm}$ was $\mathrm{dn} / \mathrm{dc}=0.130 \mathrm{~mL} \cdot \mathrm{g}^{-1}$ [50].

\subsection{Determination of the weight-average hydrodynamic radius $\boldsymbol{R}_{h}$ and of the $\boldsymbol{R}_{h}$ distribution by Taylor dispersion analysis}

TDA experiments were performed on a PACE MDQ Beckman Coulter (Fullerton, CA) apparatus. Capillaries were prepared from bare silica tubing purchased from Composite Metal Services (Worcester, United Kingdom). The capillary dimensions were $40 \mathrm{~cm}$ (30 cm to the detector $) \times 50 \mu \mathrm{m}$ I.D. New capillaries were conditioned with the following flushes: $1 \mathrm{M}$ 
$\mathrm{NaOH}$ for $30 \mathrm{~min}$ and water for $10 \mathrm{~min}$. Before sample injection, the capillary was filled with

cyclohexane $\left(8.62 \times 10^{-4}\right.$ Pa.s viscosity). Between two TDA analyses, the capillary was flushed with cyclohexane (30 psi for $2 \mathrm{~min}$ ). A mobilization pressure of 1 psi ( 71 mbar) was applied with cyclohexane vials at both ends of the capillary, resulting in a flow rate of 184 $\mathrm{nL} \cdot \mathrm{min}^{-1}$. Samples were dissolved in cyclohexane at a concentration of $1 \mathrm{~g} / \mathrm{L}$. Sample injection $(2.8 \mathrm{~nL})$ was performed hydrodynamically on the inlet side of the capillary $(0.3 \mathrm{psi}$ for $3 \mathrm{~s} ; \sim 1 \%$ of the capillary volume). Solutes were monitored by UV absorbance at a wavelength of $200 \mathrm{~nm}$. The elution time was systematically corrected for the delay in the application of the pressure (pressure ramp time, $15 \mathrm{~s}$ ) by subtracting $7.5 \mathrm{~s}$ (half-time of the pressure ramp) to the recorded elution time. The temperature of the capillary cartridge was set at $25^{\circ} \mathrm{C}$.

Two different methods were used to determine the weight-average hydrodynamic radius by TDA. The first method (method 1) is based on the integration of the Taylorgram [22], and the second method (method 2) is based on a deconvolution of the Taylorgram using a recently published Constrained Regularized Linear Inversion (CRLI) method [45].

In method 1 , the average diffusion coefficient $D$ is obtained by integration of the Taylorgram (or temporal elution profile) in order to calculate the temporal variance of the Taylorgram, $\sigma^{2}$. The integration of the elution profile was performed using the discrete form of the following equation [22]:

$$
\sigma^{2}=\frac{\int S(t)\left(t-t_{0}\right)^{2} d t}{\int S(t) d t}=\frac{\sum_{i=n}^{m} S_{i}\left(t_{i}-t_{0}\right)^{2}\left(t_{i+1}-t_{i}\right)}{\sum_{i=n}^{m} S_{i}\left(t_{i+1}-t_{i}\right)}
$$

where $S(t)$ is the detector response, $t_{i}$ is the elution time for a given point $i$ of the Taylorgram and $t_{0}$ is the average elution time. $n$ and $m$ are the starting and ending points that are considered for the integration of the Taylorgram.

The integration of the Taylorgram was only performed on the left part of the elution profile (the end point was $t_{0}$ ), before and after subtracting the Gaussian contribution due to the small molecules (see results and discussion section). Corrections of the temporal variance and average detection time due to the injected volume were also taken into account, as described elsewhere [29], but these corrections are negligible when the injected volume is $\leq 1 \%$ of the capillary volume to the detection point [22], as is the case here. Finally, the so called Taylor average diffusion coefficient $\langle D\rangle_{T D A}$ is obtained from:

$$
\langle D\rangle_{T D A}=\frac{R_{c}^{2} t_{\mathrm{o}}}{24 \sigma^{2}}
$$

where $R_{c}$ is the capillary radius. 
Equation (2) is valid as far as $\frac{\langle D\rangle_{T D A} t_{0}}{R_{c}^{2}} \geq 1.25[\mathbf{1 8}, \mathbf{2 4}]$ to ensure that the analysis time is larger than the characteristic diffusion time of the solutes over the capillary cross section. Equation (2) is also only valid if the axial diffusion can be neglected compared to the Taylor dispersion contribution. This latter condition is fulfilled if $\frac{R_{C} u}{\langle D\rangle_{T D A}} \geq 40$, where $u$ is the linear velocity of the mobile phase $[\mathbf{1 8}, \mathbf{2 4}]$. It is worth noting that the Taylor average diffusion coefficient obtained by integration of the Taylorgram (method 1) is a weight harmonic average diffusion coefficient defined by:

$$
\langle D\rangle_{T D A}=\left[\overline{D^{-1}}\right]^{-1}=\left[\int_{0}^{\infty} P_{D}(D) D^{-1} d D\right]^{-1}
$$

where $P_{D}(D)$ is the (mass-weighted) probability distribution function (PDF) of the diffusion coefficient. The TDA weight-average hydrodynamic radius $\left\langle R_{h}\right\rangle_{T D A}$ is finally determined using the Stokes-Einstein relationship:

$$
\left\langle R_{h}\right\rangle_{T D A}=\frac{k_{B} T}{6 \pi \eta\langle D\rangle_{T D A}}
$$

where $k_{B}$ is the Boltzmann constant, $T$ the temperature $(\mathrm{K})$ and $\eta$ the viscosity of the carrier liquid (Pa.s).

Method 2 is based on a recently developed Constrained Regularized Linear Inversion (CRLI) approach [45]. This method allows the PDF of the hydrodynamic radius to be extracted from the experimental Taylorgrams. In brief, this method consists of introducing additional constraints in the usual least-squares fitting of the Taylorgram ("regularization"), in order to reject non-physical solutions, finally converging to the desired PDF of the hydrodynamic radius, $P_{R}\left(R_{h}\right)$. Typically, the constraints penalize those solutions for which $\partial^{2} P_{R} / \partial R^{2}$ is, on average, too large, i.e. those PDFs that exhibit too detailed a structure, see Ref. [45] for more details.

The CRLI algorithm inverts the following relationship relating the Taylorgram to $P_{R}\left(R_{h}\right)$ [45]:

$$
S(t)=\frac{k_{R} m_{t o t}}{Q} \sqrt{\frac{\lambda_{R}}{\pi}} \int_{0}^{\infty} \frac{P_{R}\left(R_{h}\right)}{\sqrt{R_{h}}} \exp \left[-\frac{\lambda_{R}\left(t-t_{0}\right)^{2}}{R_{h}}\right] \mathrm{d} R_{h}
$$

where $k_{R}$ is the detector response factor, $m_{\text {tot }}$ the total sample mass injected, $Q$ the carrier liquid flow-rate and with

$$
\lambda_{R}=\frac{2 k_{B} T}{\pi R_{c}^{2} t_{0} \eta}
$$


After normalization, eq. (5) reduces to:

$$
s(t)=\frac{S(t)}{S\left(t_{0}\right)}=c_{R} \int_{0}^{\infty} \frac{P_{R}\left(R_{h}\right)}{\sqrt{R_{h}}} \exp \left[-\frac{\lambda_{R}\left(t-t_{0}\right)^{2}}{R_{h}}\right] \mathrm{d} R_{h}
$$

with

$$
c_{R}=\left[\int_{0}^{\infty} \frac{P_{R}\left(R_{h}\right)}{\sqrt{R_{h}}} \mathrm{~d} R_{h}\right]^{-1}=\left[\overline{R_{h}^{-1 / 2}}\right]^{-1}
$$

The PDFs of $R_{h}$ reported in the following are obtained by averaging individual distributions measured in 2 to 5 independent repetitions. For each sample, a mass-average $R_{h}$ value was calculated from $P_{R}\left(R_{h}\right)$, via:

$$
\left\langle R_{h}\right\rangle_{C R L I}=\frac{\int_{0}^{\infty} R_{h} \times P_{R}\left(R_{h}\right) \mathrm{d} R_{h}}{\int_{0}^{\infty} P_{R}\left(R_{h}\right) \mathrm{d} R_{h}}
$$

\section{Results and discussion}

Our main objective is to compare the average radii and the $R_{h}$ PDFs obtained by SEC and by TDA on different PI standards, industrial PI and natural rubbers (NR).

\subsection{Determination of the average hydrodynamic radius by TDA}

Examples of raw Taylorgrams obtained for the polyisoprene (PI) standards are displayed in Figure 1A. Each Taylorgram has been normalized by the maximum absorbance at $t=t_{0}$. $\mathrm{A}$ quite good baseline return and peak symmetry is seen in Figure 1A. It is clearly observed that the higher the molar mass, the broader the Taylorgram, due to the higher Taylor dispersion for the species with lower diffusion coefficient. Nevertheless, some PI standards contain a tiny amount of small molecules (possibly monomers, residual solvent) absorbing at the detection wavelength $(200 \mathrm{~nm})$. This small molecule contribution appears as a thin peak, most notable for the 361 and $766 \times 10^{3} \mathrm{~g} / \mathrm{mol}$ PI standards (blue and green lines in Figure $1 \mathrm{~A})$. The contribution due to the small molecules should not be taken into account in the data analysis. Accordingly, we systematically corrected for it by subtracting the corresponding Gaussian peak from the raw data, leading to the Taylorgrams presented in 
Figure 1B [51]. The corresponding weight-average Rhydrodynamic radii obtained by integration of the Taylorgrams presented in Figure 1B (method $1,\left\langle R_{h}\right\rangle_{T D A}$ ) are gathered in Table 1. For the sake of comparison, the $R_{h}$ values obtained without subtraction of the small molecule contribution are also given in Table 1 . The impact of the small molecule contribution on the average $R_{h}$ value is less than $3 \%$.

\section{$<$ Figure 1>}

The same data processing was applied to the industrial PI samples (IR2200, IR307 and IR309) and the natural rubber samples (NR1 and NR2). The raw Taylorgrams and the corrected ones are displayed in Figures $2 \mathrm{~A}$ and $2 \mathrm{~B}$ for industrial PI, and Figures $3 \mathrm{~A}$ and $3 \mathrm{~B}$ for NR, respectively. It should be noticed that the symmetry of the Taylorgrams was not perfect, especially in the case of NR. This may be due to some polymer adsorption onto the capillary surface. This is why the Taylorgrams were analyzed on the left part, where adsorption has a much lower impact. The contribution of the small molecules to the average $R_{h}$ value is less than $6 \%$ (see Table 1 ). The correlation between the hydrodynamic radius (method $1,\left\langle R_{h}\right\rangle_{T D A}$ ) and the PI weight average molar mass $\left(M_{w}, \mathrm{SEC}\right)$ is given in Figure 4. For a random coil in a good solvent, the theoretical value of the exponent $b$ of the power law $R_{h}=a M_{w}^{b}$ is predicted to be 0.588 [52]. This value was confirmed experimentally using light scattering, for PI in cyclohexane (Fetters et al., $b=0.592$ [53]) and in tetrahydrofuran (Kim et al., $b=0.606$ [14]). In our experiments, we find an exponent $b=0.54+/-0.06$ (confidence interval at 95\%) for the seven PI standards, slightly lower than the expected theoretical value. Industrial PI grades and NR samples are close to the scaling law obtained for the PI standards (see Figure 4).

\section{$<$ Table 1> \\ <Figure 2> \\ $<$ Figure 3> \\ <Figure 4>}

\subsection{Hydrodynamic radius distributions obtained by TDA and comparison with SEC}

The elution profile in SEC gives access to the size distribution of the polymers, since the separation parameter in SEC is the hydrodynamic volume of the solute. For the SEC 
measurements, THF was used as the eluent. THF gives a higher signal for the LS and refractive index analysis, thanks to a higher $\mathrm{dn} / \mathrm{dc}$ compared to cyclohexane. For the TDA analysis, by contrast, cyclohexane is the best choice, since THF is incompatible with UV detection and with the TDA setup (THF dissolves the MDQ Beckman Coulter plastic interface in contact with the sample and eluent vials). In spite of the need to use different solvents, the comparison between the TDA and SEC-MALS results for the same PI and rubber samples sheds light on the strengths and limitations of each method.

In SEC, the logarithm of the hydrodynamic radius is a decreasing linear function of the elution volume. In the elution profile, the refractive index (RI) detector yields a signal proportional to the polymer mass concentration. The MALS detector combined with the RI detector allows the polymer molar mass to be measured. All the 3 industrial PI analyzed by SEC-MALS exhibited a main peak eluting at about 16-17 min, followed by one or two other modes eluting between 18-22 min, which were more or less separated depending on the sample. IR309 appeared as a tri-modal elution profile (see Figure 5A), while the two other samples (IR307 and IR2200) presented unresolved shoulders. Figure 5B shows hydrodynamic radius $\left(R_{h}\right)$ mass-distributions obtained by SEC assuming that $R_{g} / R_{h}=1.78$, as expected for monodisperse random coils in good solvent [52]. Indeed, SEC coupled to a MALS detector allows determining, for each slice of the chromatogram, both the molar mass $\left(M_{i}\right)$ and the radius of gyration $\left(R_{g i}\right)$. The $R_{h i}$ were calculated from the $R_{g i}$ for each slice of the chromatogram using $R_{g} / R_{h}=1.78$ relationship. In the SEC analysis, all samples display rather broad distributions with an unresolved shoulder for IR2200 and IR307, and three partially resolved modes for IR309. The $R_{h}$ corresponding to the peak maximum for the mass-distribution of $R_{h}$ determined from the SEC data (Figure 5B) were $32 \mathrm{~nm}$ for IR2200, $45 \mathrm{~nm}$ for IR309 and $47 \mathrm{~nm}$ for IR307.

Figure $5 \mathrm{C}$ displays the hydrodynamic radius distributions obtained by TDA after data processing of the Taylorgrams from Figure 2A according to method 2 (CRLI, see section 2.3). Size distributions obtained by TDA display two well-defined main modes, and a less important (minor) third mode (see inset of Figure $5 \mathrm{C}$ ), corresponding to low molar mass polymers (oligomers) or monomers with $R_{h}$ below $3 \mathrm{~nm}$. These oligomers/monomers appear as a sharp peak in the Taylorgrams presented in Figure 2A. All IR samples display a main mode at $R_{h}$ ranking between 30 and $50 \mathrm{~nm}$ (peak apex at $34.8 \mathrm{~nm}$ for IR 2200, $41.4 \mathrm{~nm}$ for IR 309 and 42.3 for IR 307). These $R_{h}$ values are in reasonably good agreement with SEC analysis, given that the solvents are different and taking into account the uncertainty in the actual value of $R_{g} / R_{h}$ required to calculate the $R_{h}$ PDF from the SEC data. A second mode in the $R_{h}$ distribution was observed by TDA, corresponding to sizes between 5 and $11 \mathrm{~nm}$ (peak apex at $10.6 \mathrm{~nm}$ for IR 2200, 9.6 for IR 309 and at $5.6 \mathrm{~nm}$ for IR 307). This peak is not 
resolved in the PDF calculated from the SEC data, except perhaps for the IR 309 sample, which exhibits a pronounced shoulder in the 10-20 nm range. Overall, TDA showed was better resolution for the size characterization of the IR samples compared to SEC.

\section{$<$ Figure 5>}

For natural rubber (NR) samples, the TDA analysis again gave $R_{h}$ profiles with better size resolution than those retrieved from the SEC elution profiles (Figure 6). The SEC data exhibited elution profiles rather unimodal, with a more or less pronounced shoulder. Unlike the PI industrial samples, for the NR samples, it is not possible to assume that each slice of the chromatogram is only composed of monodisperse random coils, because of the coelution of microaggregates and random coil macromolecules [13]. For this reason, it was not possible to calculate the $R_{h}$ PDF. By contrast, in TDA, $R_{h}$ is directly determined, with no need of making any assumptions on the nature of the sample (e.g. on the presence of aggregates). As displayed in Figure 6B, the NR samples had trimodal $R_{h}$ profiles with small oligomers $\left(R_{h}\right.$ below $2-3 \mathrm{~nm}$ ) and two larger polymer modes at 7-10 nm and 20-60 nm, respectively. Remarkably, the TDA analysis reveals unambiguous differences in the position and the width of the peaks for the two samples, not captured by SEC. In particular, the peak for the largest sizes shifts from $37 \mathrm{~nm}$ for NR1 to $40 \mathrm{~nm}$ for NR2. As explained above, it was not possible to determine the $R_{h}$ PDF from the SEC data. However, we note that the ranking in the SEC elution curves is consistent with the TDA data, since NR2 is eluted before NR1, indicative of a larger size.

From the $R_{h}$ distribution obtained by method 2 , it is also possible to determine a weightaverage $R_{h}$ by integration on the whole distribution (see Eq. 9). We exclude the contribution of the small molecules, $R_{h}<3 \mathrm{~nm}$, consistentl with the subtraction performed in method 1 . The results are presented in Table 1: we find a difference of less than $3 \%$ between the two methods. This demonstrates the excellent agreement between the two different ways to process the Taylorgrams, thereby confirming the robustness of the methods of analysis presented here.

\section{$<$ Figure 6>}

\section{Conclusions}

We have demonstrated that TDA can be used in non-aqueous media (cyclohexane in the present study) for the analysis of PI in industrial and natural rubbers. Because TDA is implemented in open capillary tubes, it is much less influenced by undesirable interactions as compared to SEC, where microaggregates from NR samples (hydrodynamic radii $~ 40-50 \mathrm{~nm}$ ) 
may result in abnormal elution curves at large elution times. By leveraging on the

constrained regularized linear inversion (CRLI) method, not only does TDA give access to the weight average hydrodynamic radius, it also provides the full hydrodynamic radius distribution. While under some conditions SEC data can yield the PDF of $R_{\mathrm{h}}$, the present work shows that TDA has a broader applicability and a superior ability to resolve the various modes contributing to the sample size distribution in a large range of hydrodynamic radii from $\sim 1$ to $100 \mathrm{~nm}$. Given the strengths of the method and the advantages of modern TDA in its miniaturized version (low sample volume $\sim \mathrm{nL}$, low solvent consumption, fast analysis (a few min), absolute determination, simple instrumentation and straightforward methodology), there is no doubt that TDA holds great potential for quality control and production monitoring of $\mathrm{PI}$ in the rubber industry. Possible future work could be to investigate new capillary coatings and/or capillary i.d. to improve the peak symmetry, especially in the case of NR analysis.

\section{References}

[1] C. Kim, M. Morel, J. Sainte Beuve, S. Guilbert, F. Bonfils, Better Characterization of Raw Natural Rubber by Decreasing the Rotor Speed of Mooney Viscometer: Role of Macromolecular Structure, Polym Eng Sci, 50 (2010) 240-248.

[2] C.M. Lotti, R.M.B. Moreno, P.S. Gonçalves, S. Bhattacharya, L.H.C. Mattoso, Extensional Rheology of Raw Natural Rubber From New Clones of Hevea brasiliensis, Polym Eng Sci, 52 (2012) 139-148.

[3] M. Ferreira, R.M.B. Moreno, P.S. Gonçalves, L.H.C. Mattoso, Evaluation of natural rubber clones of Hevea brasiliensis, Rubb Chem Technol, 75 (2002) 171-178.

[4] E.E. Ehabe, Y. Leroux, F. Ngolemasango, F. Bonfils, G. Nkeng, B. Nkouonkam, J. Sainte Beuve, Effect of the maturation on the bulk viscosity and molecular chain length of cuplump NR, J Appl Polym Sci, 86 (2002) 703-708.

[5] Jie-Ping Zhong, Si-Dong Li, Ling-Xue Kong, Lei Yang, Shuang-Quan Liao, Xiao-Dong She, Study on the Properties of Natural Rubber during Maturation, J Polym Mater, 26 (2009) 351360.

[6] J. Intapun, J. Sainte Beuve, F. Bonfils, V. Tanrattanakul, E. Dubreucq, L. Vaysse, Effect of micro-organisms during initial coagula maturation of Hevea natural rubber, J Appl Polym Sci, 118 (2010) 1341-1348.

[7] K.N.G. Fuller, Rheology of raw rubber, in: A. Roberts (Ed.) Natural Rubber Science and Technology, Oxford University Press, Oxford, 1988, pp. 141-176.

[8] L. Vaysse, F. Bonfils, J. Sainte-Beuve, M. Cartault, Natural Rubber, in: K. Matyjaszewski, M. Möller (Eds.) Polymer Science, A Comprehensive Reference, Elsevier BV, Amsterdam, 2012, pp. 281-293.

[9] P.W. Allen, G.M. Bristow, The gel phase in natural rubber, Rubb Chem Technol, 36 (1963) 1024-1034.

[10] E.E. Ehabe, F. Bonfils, Novel insight into the gel phase of hevea natural rubber, J Rubb Res, 14 (2011) 1-10.

[11] S. Amnuaypornsri, J. Sakdapipanich, S. Toki, B. Hsiao, N. Ichikawa, Y. Tanaka, Straininduced crystallization of natural rubber: Effect of proteins and phospholipids, Rubb Chem Technol, 81 (2008) 753-766.

[12] Y. Tanaka, L. Tarachiwin, Recent advances in structural characterization of natural rubber, Rubb Chem Technol, 82 (2009) 283-314. 
[13] C. Kim, M. Morel, J. Sainte Beuve, A. Collet, S. Guilbert, F. Bonfils, Characterization of natural rubber using size-exclusion chromatography with online multi-angle light scattering Study of the phenomenon behind the abnormal elution profile, J Chromato A, 1213 (2008) 181-188.

[14] C. Kim, J. Sainte Beuve, S. Guilbert, F. Bonfils, Study of chain branching in natural rubber using size-exclusion chromatography coupled with a multi-angle light scattering detector (SEC-MALS), Eur. Polym. J., 45 (2009) 2249-2259.

[15] S. Dubascoux, C. Thepchalerm, E. Dubreucq, S. Wisunthorn, L. Vaysse, S. Kiatkamjornwong, C. Nakason, F. Bonfils, Comparative study of mesostructure of natural and synthetic polyisoprene by SEC-MALS and AF4-MALS, J Chromato A, 1224 (2012) 27-34.

[16] V.A. Grechanovskii, I.P. Dmitrieva, N.B. Zaitsev, Separation and preliminary characterisation of the protein component from commercial varieties of hevea rubber, International polymer science and technology, 14 (1987) 1-4.

[17] S.N. Gan, Storage hardening of Natural Rubber, J Membrane Sci, Pure Appl Chem, A33 (1996) 1939-1948.

[18] G. Taylor, Dispersion of Soluble Matter in Solvent Flowing Slowly through a Tube, Proceeding of the Royal Society of London Series A, 219 (1953) 186-203.

[19] M. Bello, R. Rezzonico,P. Righetti, Use of Taylor-Aris Dispersion for Measurement of a Solute Diffusion Coefficient in Thin Capillaries, Science, 226 (1994) 773-778.

[20] U.G. Sharma, N; Carbeck, J, Diffusivity of Solutes Measured in Glass Capillaries Using Taylor's Analysis of Dispersion and a Commercial CE Instrument, Anal Chem, 77 (2005) 806813.

[21] F.V. d'Orlye, A. Varenne; P. Gareil, Determination of nanoparticle diffusion coefficients by Taylor dispersion analysis using a capillary electrophoresis instrument, J Chromatogr A, 1204 (2008) 226-232.

[22] H. Cottet, J. Chamieh, Comparison of Single and Double Detection Points of Taylor Dispersion Analysis for Monodisperse and Polydisperse Samples, J Chromatogr A, 1241 (2012) 123-127.

[23] A.M. Lewandrowska, A. Majchere, A. Ochab-Marcinek, et al. Taylor Dispersion Analysis in Coiled Capillaries at High Flow Rates, Anal Chem, 85 (2013) 4051-4056.

[24] H. Cottet, J-P Biron, M. Martin, On the optimization of operating conditions for Taylor dispersion analysis of mixtures, Analyst, 139 (2014) 3552-3562.

[25] W.L. Hulse, J. Gray, R.T. Forbes, Evaluating the inter and intra batch variability of protein aggregation behaviour using Taylor dispersion analysis and dynamic light scattering, International Journal of Pharmaceutics, 453 (2013) 351-357.

[26] W.L. Hulse, R.T. Forbes, A Taylor dispersion analysis method for the sizing of therapeutic proteins and their aggregates using nanolitre sample quantities, International Journal of Pharmaceutics, 416 (2011) 394-397.

[27] A. Lavoisier, J-M. Schlaeppi, Early developability screen of therapeutic antibody candidates using Taylor dispersion analysis and UV area imaging detection, mAbs, 7 (2015) 77-83.

[28] E.P.C. Mes, W.T. Kok, H. Poppe, et al., Comparison of methods for the determination of diffusion coefficients of polymers in dilute solutions: The influence of polydispersity, J Polym Sci, Part B Polym Physics, 37 (1999) 593-603.

[29] H. Cottet, M. Martin, A. Papillaud, et al. , Determination of dendrigraft poly-L-lysine diffusion coefficients by Taylor dispersion analysis, Biomacromolecules, 8 (2007) 3235-3243.

[30] J. Deschamps, S.G. Dutremez, B. Boury, et al. , Size-Based Characterization of an Ionic Polydiacetylene by Taylor Dispersion Analysis and Capillary Electrophoresis, Macromolecules, 42 (2009) 2679-2685.

[31] F. Oukacine, S. Bernard, I. Bobe, et al., Physico-chemical characterization of polymeric micelles loaded with platinum derivatives by capillary electrophoresis and related methods, J Control Release, 196 (2014) 139-145. 
[32] A. Ibrahim, R. Meyrueis, G. Pouliquen, et al., Size land charge characterization of polymeric drug delivery systems by Taylor dispersion analysis and capillary electrophoresis, Anal Bioanal Chem, 405 (2013) 5369-5379.

[33] B. Belongia, J. Baygents, Measurements on the Diffusion Coefficient of Colloidal Particles by Taylor-Aris Dispersion, J Colloid Interf Sci, 195 (1997) 19-31.

[34] F. Oukacine, A. Morel, I. Desvignes, et al. , Size-based characterization of nanoparticle mixtures by the inline coupling of capillary electrophoresis to Taylor dispersion analysis, J Chromatogr A, 1426 (2015) 220-225.

[35] L. Leclercq, S. Reinhard, J. Chamieh, et al., Fast Characterization of Polyplexes by Taylor Dispersion Analysis, Macromolecules, 48 (2015) 7216-7221.

[36] F. Ye, H. Jensen, S.W. Larsen, et al., Measurement of drug diffusivities in pharmaceutical solvents using Taylor dispersion analysis, J Pharmaceut Biomed Analysis, 61 (2012) 176-183.

[37] H. Jensen, S.W. Larsen, C. Larsen, et al., Physicochemical profiling of drug candidates using capillary-based techniques J Drug Deliv Sci Tec, 23 (2013) 333-345.

[38] J. Chamieh, F. Davanier, V. Jannin, et al., Size characterization of commercial micelles and microemulsions by Taylor dispersion analysis, Int J Pharmaceu, 492 (2015) 46-54.

[39] K. MacEwan, D.G. Leaist, Quaternary mutual diffusion coefficients for aqueous solutions of a cationic-anionic mixed surfactant from moments analysis of Taylor dispersion profiles, Physical Chemistry Chemical Physics, 5 (2003) 3951-3958.

[40] N.N. Poulsen, N.Z. Andersen, J. Ostergaard, et al. , Flow induced dispersion analysis rapidly quantifies proteins in human plasma samples, Analyst, 140 (2015) 4365-4369.

[41] S. Latunde-Dada, R. Bott, D. Barker, et al., Methodologies for the rapid determination of the diffusion interaction parameter using Taylor dispersion analysis, Anal Methods, 8 (2016) 386-392.

[42] W.T. Kok, A.J. Tudos, M. Grutters, et al. , Characterization of Asphaltenes by Nonaqueous Capillary Electrophoresis, Energy \& Fuels, 25 (2011) 208-214.

[43] M. Ghanavati, H. Hassanzadeh, J. Abedi, Application of taylor dispersion technique to measure mutual diffusion coefficient in hexane plus bitumen system, AIChE Journal, 60 (2014) 2670-2682.

[44] H. Cottet, J-P Biron, M. Martin, Taylor dispersion Analysis of mixtures, Anal Chem, 79 (2007) 9066-9073.

[45] L. Cipelletti, J-P Biron, M. Martin, et al., Measuring Arbitrary Diffusion Coefficient Distributions of Nano-Objects by Taylor Dispersion Analysis, Anal Chem, 87 (2015) 84898496.

[46] L. Cipelletti, J-P Biron, M. Martin, et al., Polydispersity Analysis of Taylor Dispersion Data: The Cumulant Method, Anal Chem, 86 (2014) 6471-6478.

[47] B.C. Sekhar, Inhibition of hardening in natural rubber, Rubb Chem Technol, 35 (1962) 889-895.

[48] P. Wyatt, Light scattering and the absolute characterization of macromolecules, Anal Chim Acta, 272 (1993) 1-40.

[49] Y. Yu, P. DesLauriers, D.C. Rohlfing, SEC-MALS method for the determination of longchain branching and long-chain branching distribution in polyethylene, Polymer, 46 (2005) 5165-5182.

[50] C. Kim, A. Deratani, F. Bonfils, Determination of the refractive index increment of natural and synthetic poly(cis-1,4-isoprene) solutions and its effect on structural parameters, J Liq Chromatogr Related Technol, 33 (2010) 37-45.

[51] H. Cottet, J-P Biron, L. Cipelletti, et al. , Determination of Individual Diffusion Coefficients in Evolving Binary Mixtures by Taylor Dispersion Analysis: Application to the Monitoring of Polymer Reaction, Anal Chem, 82 (2010) 1793-1802.

[52] W. Burchard, Solution Properties of Branched Macromolecules, Adv Polym Sci, 143 (1999) 113. 
[53] L.J. Fetters, N. Hadjichristidis, J.S. Lindner, J.W. Mays, Molecular Weight Dependence of Hydrodynamic and Thermodynamic Properties for Well-Defined Linear Polymers in Solution, J Phys Chem Ref Data, 23 (1994) 619-640. 

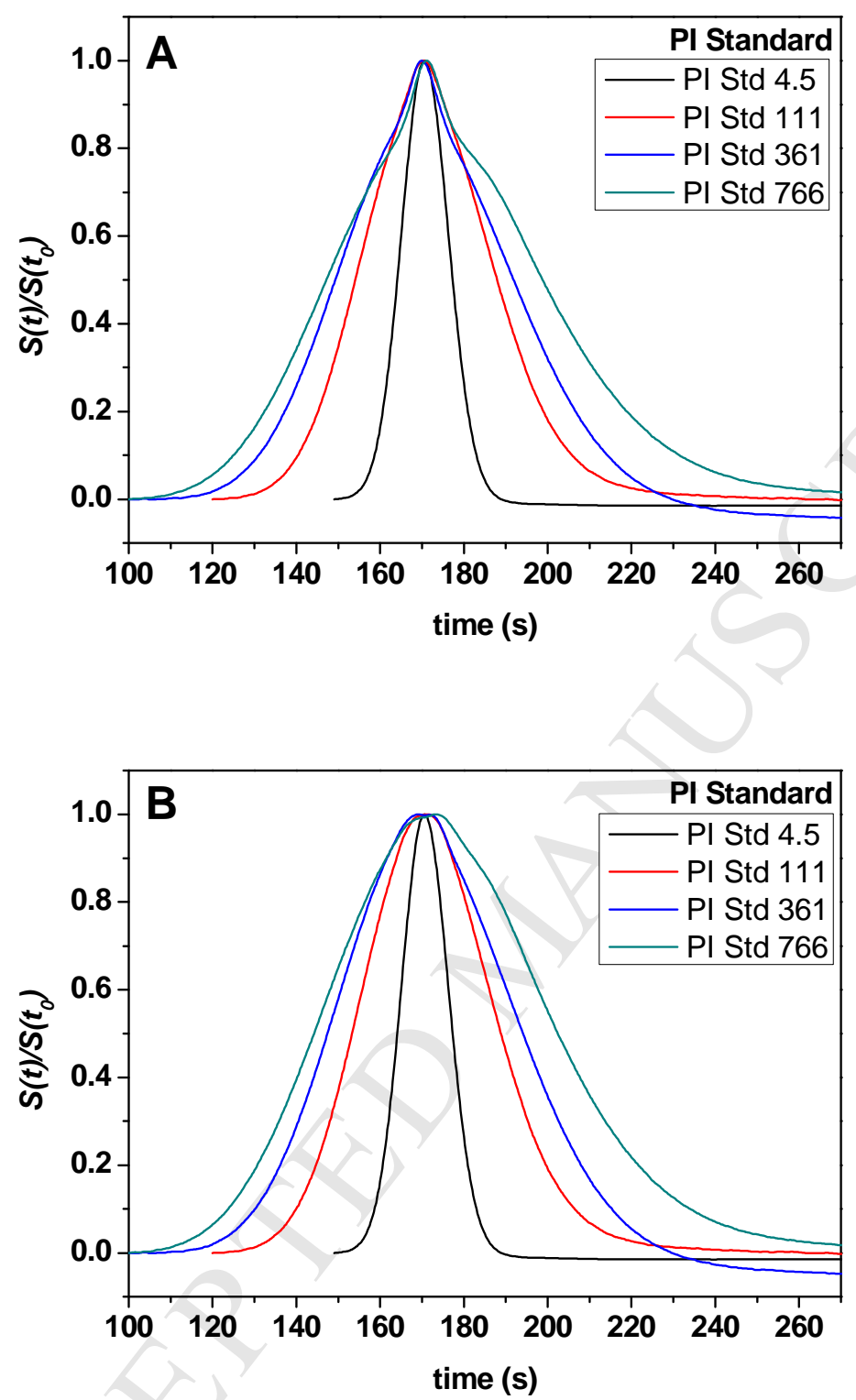

Figure 1. Taylorgrams obtained for PI standards in cyclohexane before (A) and after substraction of the contribution due to small molecules (B). Experimental conditions: fused silica capillary $40 \mathrm{~cm}$ (30 cm to the detector) x $50 \mu \mathrm{m}$ i.d. Mobile phase: cyclohexane. Hydrodynamic injection: 0.3 psi, 3 s. Mobilization pressure: 1.0 psi. Temperature: $25^{\circ} \mathrm{C}$. Samples: PI standards 4.5, 111, 361, and $766 \times 10^{3} \mathrm{~g} / \mathrm{mol}$ at $1 \mathrm{~g} / \mathrm{L}$ in cyclohexane. Detection at $200 \mathrm{~nm}$. The normalized taylorgram is presented $\left(S(t) / S\left(t_{0}\right)\right)$. 

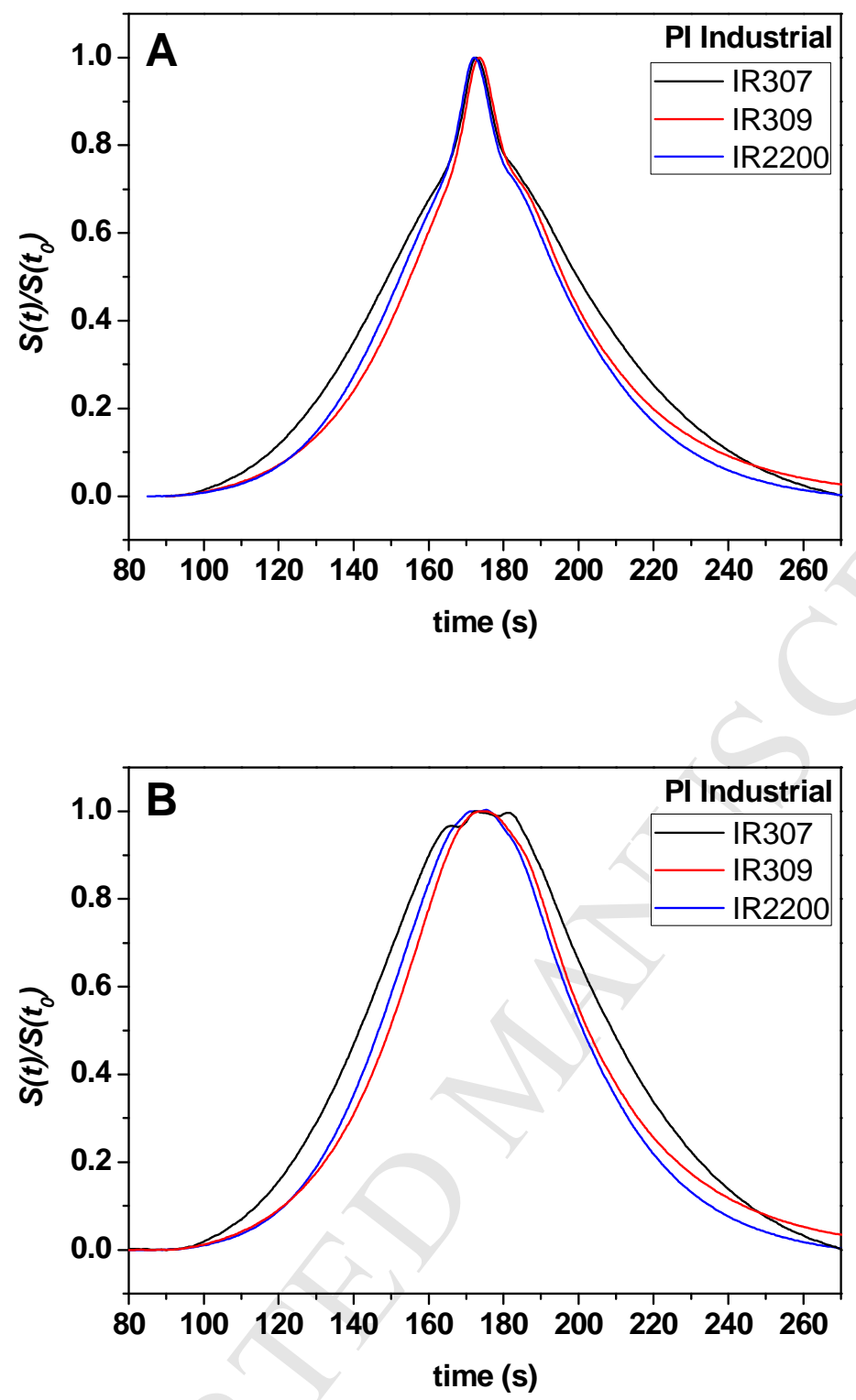

Figure 2: Taylorgrams obtained for industrial PI in cyclohexane before $(A)$ and after substraction of the contribution due to small molecules (B). Same conditions as in Figure 1. 

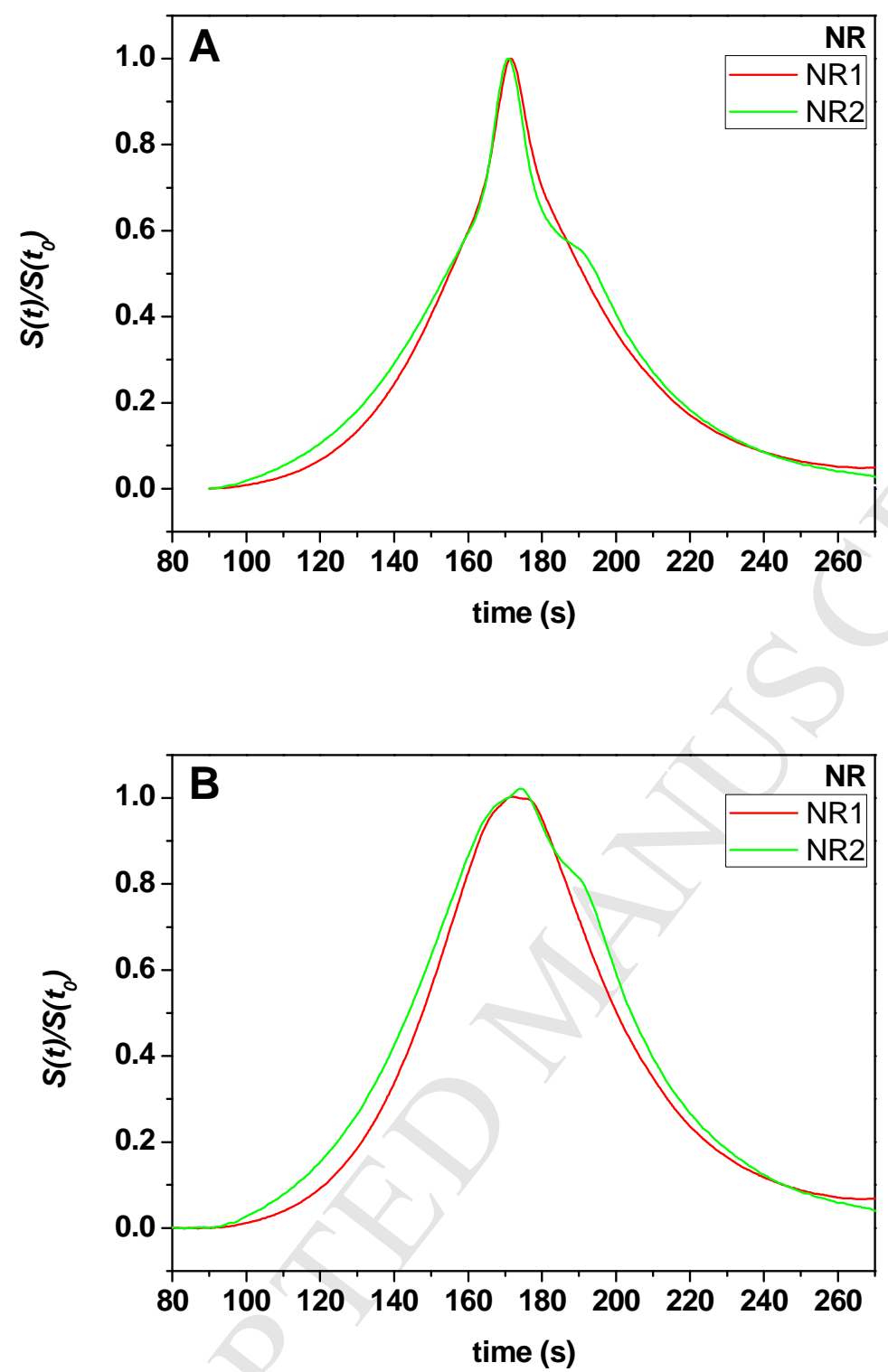

Figure 3. Taylorgrams obtained for natural rubbers (NR) in cyclohexane before (A) and after substraction of the contribution due to small molecules (B). Same conditions as in Figure 1. 


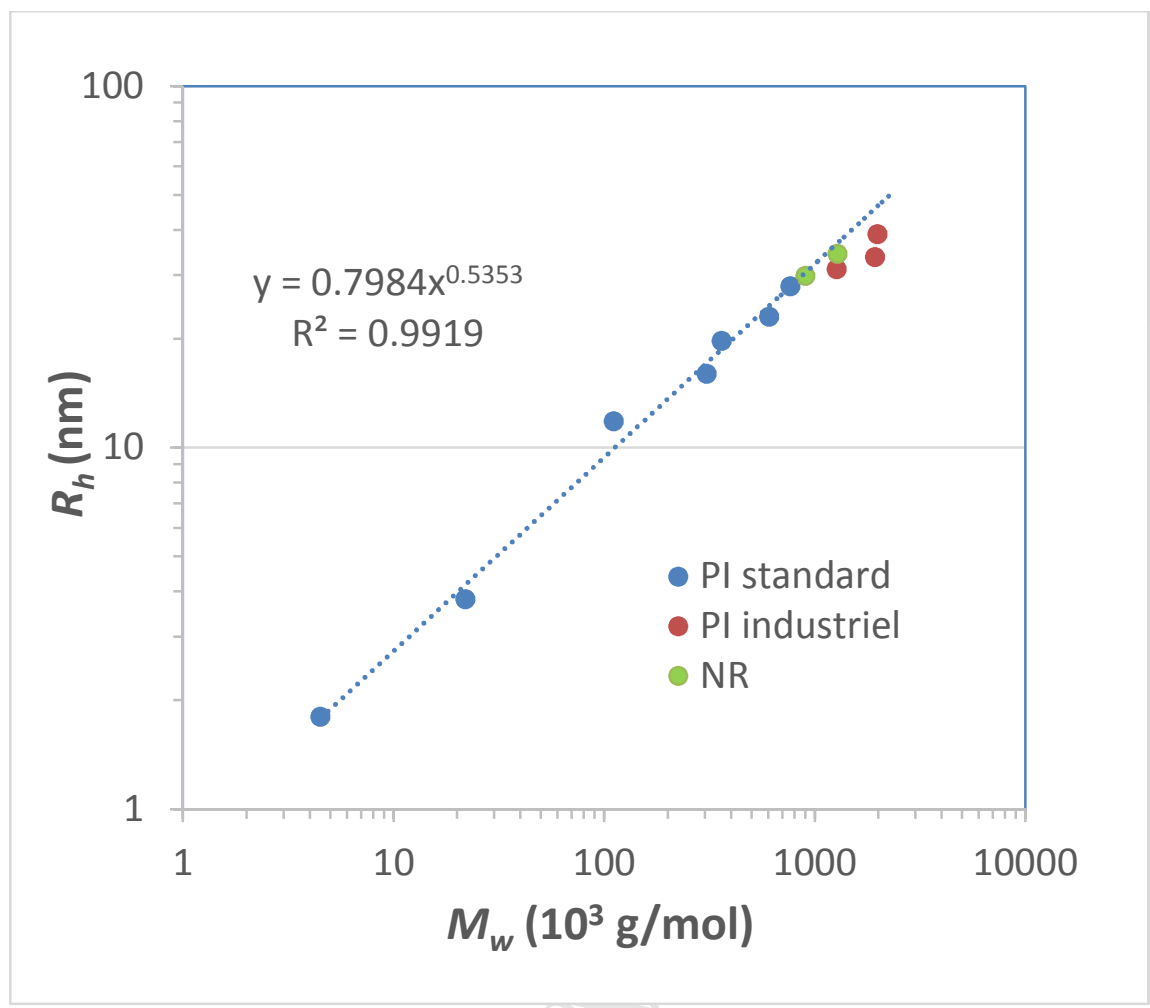

Figure 4: Log-log plot of the TDA hydrodynamic radius (method 1, after subtraction of the small molecule contribution) versus the molar mass for the PI standards, PI industrial and for NR. The dotted line is a power law fit for the PI standards. See Table 1 for the numerical values. 

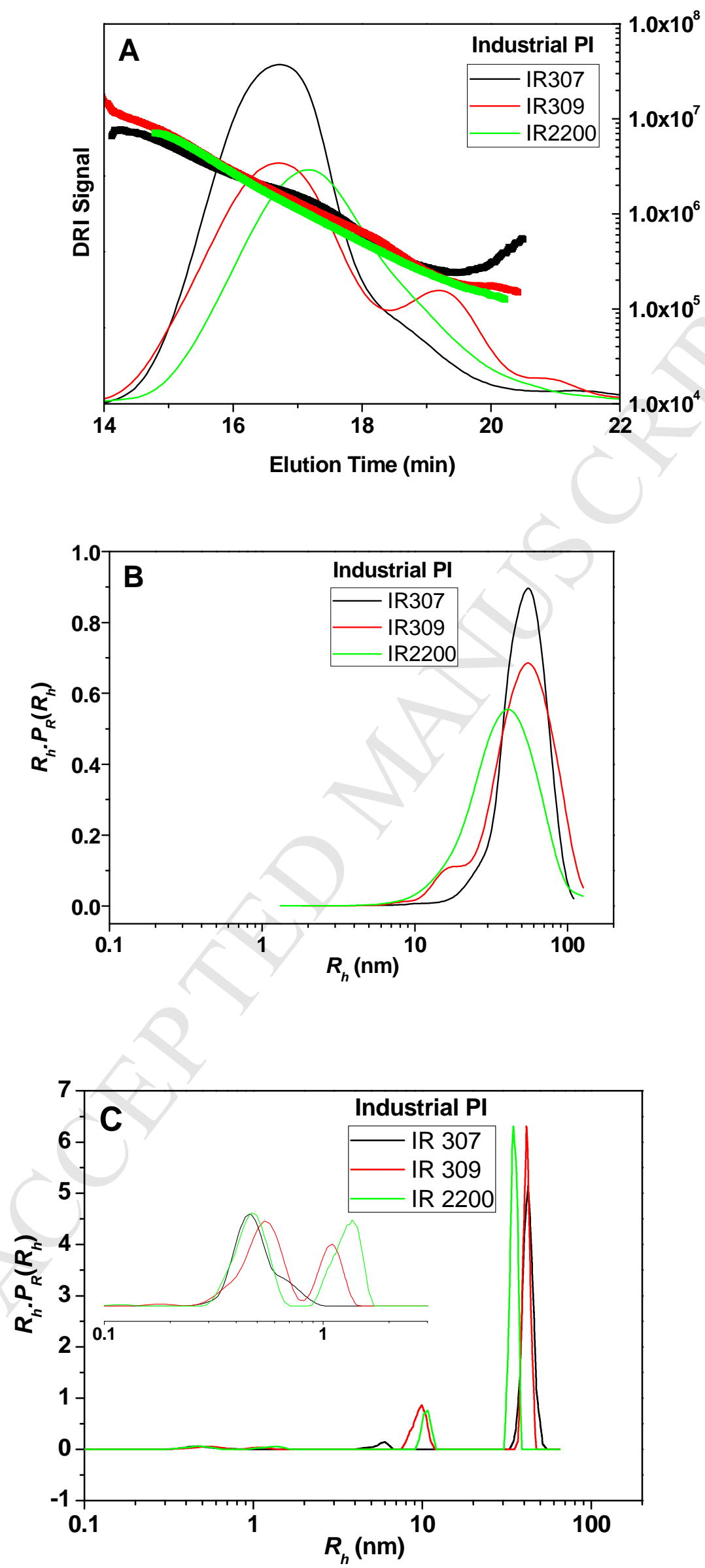
Figure 5: Elution profiles obtained by SEC (RI signal, A) and $R_{h}$ distributions obtained by SEC-MALS (B) or TDA using method 2 (C), for the 3 industrial PI samples. Experimental conditions: SEC in tetrahydrofuran, two Waters HMW6E columns $(20 \mu \mathrm{m}, 300 \mathrm{~mm} \times 7.8 \mathrm{~mm}$ I.D.) maintained at $45^{\circ} \mathrm{C}$, flow rate of $0.65 \mathrm{~mL} \cdot \mathrm{min}^{-1}$; TDA conditions as in Figure 2 . The insert in Figure $2 \mathrm{C}$ is an expanded view. $R_{h}$ distributions obtained by SEC-MALS are based on the assumption that $R_{g} / R_{h}=1.78$. 

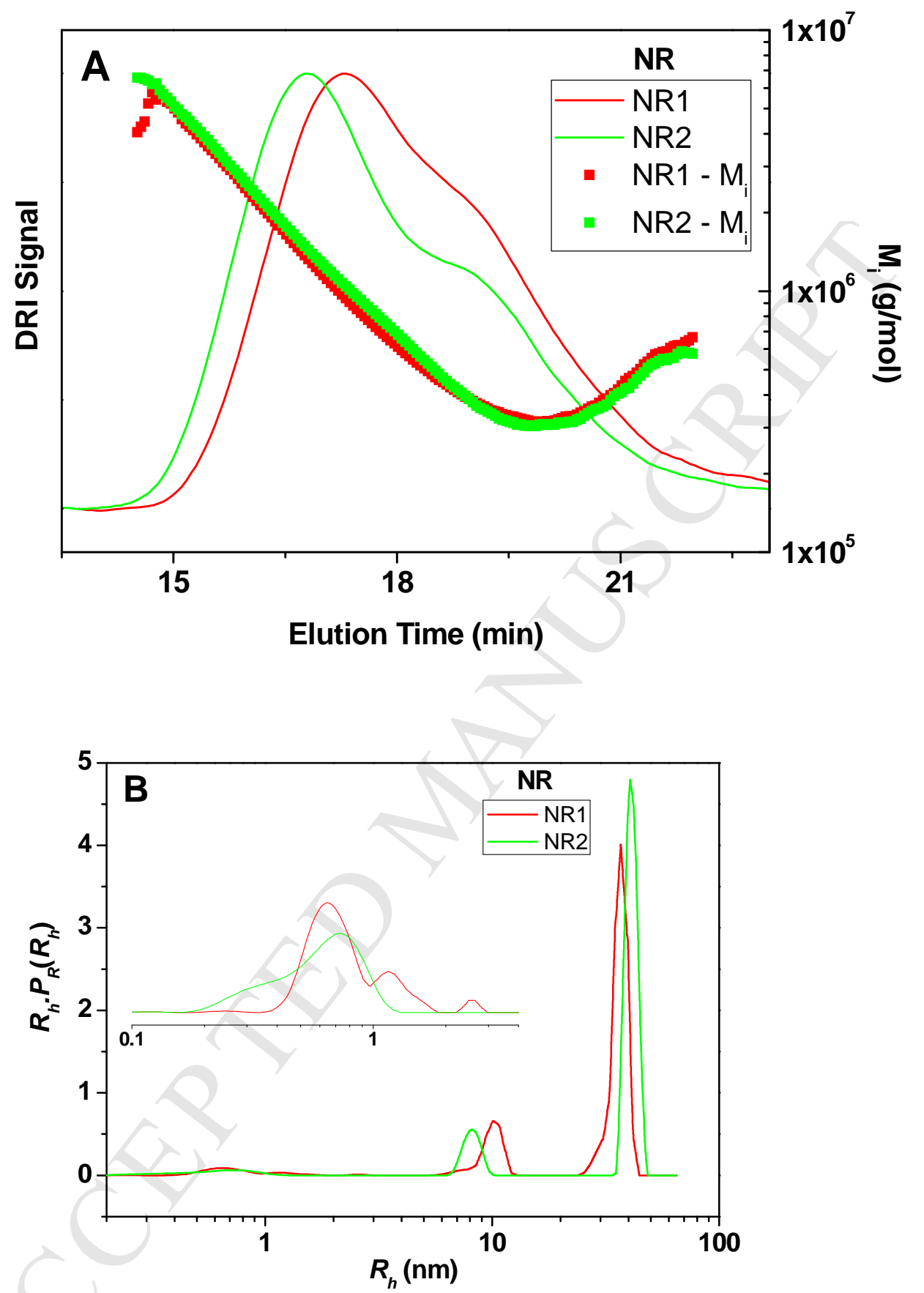

Figure 6: Elution profiles obtained by SEC (RI signal, A) and $R_{h}$ distributions obtained by TDA using method 2 (B) for two NR samples. Experimental conditions: SEC, see Figure 5; TDA, as in Figure 3. Insert in Figure 6B is an expanded view. 
Table 1: Number- and weight-average molar masses $\left(M_{n l} M_{w}\right)$, hydrodynamic radius $\left(R_{h}+/-\right.$ one standard deviation) for natural and synthetic PI. $M_{n}, M_{w}$ are determined by SEC-MALS, except for the PI standards ${ }^{\mathrm{a}}$. $R_{h}$ is determined by TDA, using both method.

\begin{tabular}{|c|c|c|c|c|c|c|c|}
\hline \multirow[t]{2}{*}{ Sample } & \multirow[t]{2}{*}{ Type } & \multirow[t]{2}{*}{$\begin{array}{c}M_{n} \\
\left(\mathrm{~kg} \cdot \mathrm{mol}^{-1}\right) \\
(1)\end{array}$} & \multirow[t]{2}{*}{$\begin{array}{c}M_{W} \\
\left(\mathrm{~kg} \cdot \mathrm{mol}^{-1}\right) \\
(1)\end{array}$} & \multicolumn{2}{|c|}{$\begin{array}{c}\left\langle R_{h}\right\rangle_{T D A}(\mathrm{~nm})^{\mathrm{b}} \\
\text { Method } 1\end{array}$} & \multicolumn{2}{|c|}{$\begin{array}{c}\left\langle R_{h}\right\rangle_{\text {CRLI }}(\mathrm{nm})^{\mathrm{b}} \\
\text { Method } 2\end{array}$} \\
\hline & & & & $\begin{array}{c}\text { with } \\
\text { substraction }^{\mathrm{c}}\end{array}$ & $\begin{array}{c}\text { without } \\
\text { substraction }^{d}\end{array}$ & $\begin{array}{c}\text { Integration } \\
\text { for } R_{h}>3 \mathrm{~nm}^{\mathrm{e}}\end{array}$ & $\begin{array}{c}\text { Integration } \\
\text { for } R_{h}>0^{f}\end{array}$ \\
\hline PI4.5 & PI Standard & 4.5 & 4.5 & $1.8 \pm 0.01$ & $1.8 \pm 0.01$ & $1.8 \pm 0.01$ & $1.8 \pm 0.01$ \\
\hline PI22 & PI Standard & 22 & 22 & $3.8 \pm 0.1$ & $3.8 \pm 0.1$ & $3.8 \pm 0.04$ & $3.8 \pm 0.04$ \\
\hline PI111 & PI Standard & 111 & 111 & $11.8 \pm 0.2$ & $11.6 \pm 0.2$ & $11.5 \pm 0.1$ & $11.4 \pm 0.1$ \\
\hline PI307 & PI Standard & 307 & 307 & $16.0 \pm 0.2$ & $15.7 \pm 0.2$ & $16.6 \pm 0.1$ & $16.2 \pm 0.1$ \\
\hline PI361 & PI Standard & 361 & 361 & $19.7 \pm 0.8$ & $19.4 \pm 0.8$ & $20.2 \pm 0.4$ & $19.9 \pm 0.4$ \\
\hline PI608 & PI Standard & 608 & 608 & $23.0 \pm 1.6$ & $16.7 \pm 1.3$ & $22.0 \pm 0.2$ & $16.2 \pm 0.5$ \\
\hline PI766 & PI Standard & 766 & 766 & $27.9 \pm 0.7$ & $27.3 \pm 0.6$ & $28.5 \pm 0.7$ & $28.0 \pm 0.7$ \\
\hline PI1040 & PI Standard & 1040 & 1040 & $28.9 \pm 0.05$ & $27.4 \pm 0.2$ & $29.9 \pm 0.2$ & $28.5 \pm 0.3$ \\
\hline IR307 & PI Industrial & 1079 & 1986 & $40.1 \pm 0.5$ & $38.9 \pm 0.5$ & $41.0 \pm 0.5$ & $39.8 \pm 0.4$ \\
\hline IR309 & PI Industrial & 652 & 1935 & $35.0 \pm 0.1$ & $33.6 \pm 0.2$ & $34.9 \pm 0.06$ & $33.5 \pm 0.03$ \\
\hline IR2200 & PI Industrial & 584 & 1271 & $32.4 \pm 0.3$ & $31.1 \pm 0.3$ & $31.7 \pm 0.2$ & $30.3 \pm 0.3$ \\
\hline NR1 & NR Industrial & 595 & 902 & $31.7 \pm 1.5$ & $29.8 \pm 1.4$ & $31.4 \pm 1.5$ & $29.5 \pm 1.4$ \\
\hline NR2 & NR Industrial & 711 & 1282 & $36.2 \pm 0.4$ & $34.3 \pm 0.5$ & $36.4 \pm 0.6$ & $34.4 \pm 0.6$ \\
\hline
\end{tabular}

${ }^{\text {a }}$ For standard polyisoprene, all $M_{n}$ and $M_{w}$ were given by the supplier.

${ }^{\mathrm{b}}$ Three repetitions in average

c Average $R_{h}$ obtained by integration of the taylorgram after subtraction of the small molecule contribution (method 1 applied to Figures 1B, 2B, 3B).

${ }^{\mathrm{d}}$ Average $R_{h}$ obtained by integration from the whole taylorgrams including the small molecule contribution (method 1 applied to Figures $1 \mathrm{~A}, 2 \mathrm{~A}, 3 \mathrm{~A}$ ).

${ }^{\text {e }}$ Average $R_{h}$ obtained by method 2 (CRLI, eq. (9)) by integration of the $\mathrm{P}_{\mathrm{R}}\left(R_{h}\right)$ distribution for $R_{h}$ higher than $3 \mathrm{~nm}$.

${ }^{\mathrm{f}}$ Average $R_{h}$ obtained by method 2 (CRLI, eq. (9)) by integration of the whole $\mathrm{P}_{\mathrm{R}}\left(R_{h}\right)$ distribution. 


\section{Highlights}

4 - Sizing natural or synthetic polyisoprenes by miniaturized Taylor dispersion analysis

5 - Full hydrodynamic radius distribution of polyisoprenes from Taylor dispersion analysis

6 - Taylor dispersion analysis has a better size-resolution compared to SEC

7 - No abnormal elution of the microaggregates in Taylor dispersion analysis

8 - Short analysis time (a few $\mathrm{min}$ ) and low sample and solvent consumption 